\title{
O Saeculum
}

Liebe Leserinnen, liebe Leser,

am 25. Oktober 1518 schrieb Ulrich von Hutten an Willibald Pirkheimer:

O saeculum, o litterae ... O Jahrhundert, o Wissenschaften, es ist eine Lust zu leben, wenn auch noch nicht, sich zur Ruhe zu setzen. Willibald. Es blühen die Studien, die Geister regen sich! Du, nimm den Strick, Barbarei, und mache Dich auf Verbannung gefasst!

Darin zeigt sich eine Jubelhaltung, ein Überschwang. Wörtlich genommen, wäre die „Barbarei“ als eine Lebensführung zu verstehen, die sich nicht der griechischen oder lateinischen Sprache bedient. Das konnte aber Hutten seinen Gegnern, den an Aristoteles gebildeten Scholastikern, nicht unterstellen. Nein, diese Briefstelle lässt lediglich den Überschwang des Jubels erkennen, der leicht zu drastischen Bildern, wie Barbarei, Strick und Verbannung findet, und es dabei eher an Logik fehlen lässt.

Was wohl hat Hutten jubeln lassen? Er nennt die Wissenschaften. Damals zählte man dazu - noch von Seneca unter Kaiser Nero so formuliert - die Studien der Theologie, der Philosophie, der Jurisprudenz und der Medizin, jeweils gestützt auf die vorher zu erlernenden „freien Künste" des Triviums (Grammatik, Logik, Dialektik) und des Quadriviums (Arithmetik, Geometrie/Geographie, Musik und Astronomie). An Überlieferung der Klassik hatte es während des Mittelalters grundsätzlich nicht gefehlt; die jeweilige Gesellschaft der Gelehrten hatte sich über Augustinus hinaus stets nach Verfügbarkeit an den Klassikern orientiert. Mit der Zeit war anderes dazu gekommen: wirtschaftliche Erfolge, wachsender Freiheitsbedarf und - „es blühen die Studien, die Geister regen sich“ neue Ideen, insgesamt, „eine Lust zu leben“. Das war in die zerbröckelnde spätmittelalterliche Welt eingedrungen, die Macht und Recht nicht recht auseinander halten konnte.

Ulrich von Hutten, der Publizist, war als solcher auf den Buchdruck angewiesen. Der Buchdruck war die epochale Erfindung seiner Zeit. Bis dahin waren Bücher zumeist von Geistlichen handgeschrieben und in Klosterbibliotheken wohl behütet aufbewahrt. Dem entsprechend waren die Inhalte zumeist mit Theologischem und weniger mit den anderen klassischen Fächern befasst. Den Schreibern und ihren Meistern galt es, das Bestehende zu bewahren und dem Neuen zu misstrauen. Missliebiges wurde auf den Index gesetzt. Ungehorsame Autoren wurden manchmal kapital bestraft. Das änderte sich nun überall. Das wohlhabendere Bürgertum konnte sich ebenfalls Bücher - zumal die Bibel - leisten. Der wachsende Umsatz ließ die "Geister sich regen“ und sorgte für Aufwertung, Verbreitung und Intensivierung der Wissenschaften. Mit anderen Worten: Die Zeit war für das Neue reif geworden; es hatte nur noch der Funke gefehlt, der die neuen Ideen zum Aufleuchten brachte. Dieser Funke war der Einfall des Johannes Gutenberg, Typen zu gießen, sie wiederverwendbar zu Druckmatrizen zusammenzusetzen; dieses aber auch kommerziell zu nutzen und so das Gedruckte unter die Leute zu bringen.

Was mich in unseren Tagen, liebe Leserinnen und Leser, an den Jubel Ulrich von Huttens erinnert, ist mein eigener Jubel ob des Internets. Es kommt immer wieder vor, dass ich konkretes Wissen suche, etwa zu Ulrich von Hutten. Dann frage ich kostenlos bei einem Internet-Suchdienst an und erhalte prompt Huttens ausführliche Vita mit anregenden Links zur erweiterten Beantwortung von Detailfragen; ich erhalte Hinweise zu praktisch beliebig vielen weiteren Fundstellen. Solches gesammelte Wissen ist nicht wie das des Konversationslexikons auf dem Stand der letzten Buchauflage eingefroren. Es wird von den Beteiligten engagiert aktuell gehalten ${ }^{1}$. Die Welt unterhält das Internet und lernt mit inm die Welt kennen. Nach Ulrich von Hutten: OO saeculum, o litterae. Iuvat vivere" ... eine Lust zu leben!"

Mit freundlichen Grüßen, Ihr

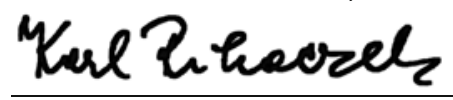

1 notwendigerweise manchmal auch zu aktuell, um als gesichert gelten zu können 